\title{
Viscosity Measurements on Ionic Liquids: A Cautionary Tale
}

\author{
João C. F. Diogo • Fernando J. P. Caetano • \\ João M. N. A. Fareleira • William A. Wakeham
}

Received: 2 November 2012 / Accepted: 25 June 2013 / Published online: 30 July 2013

(C) Springer Science+Business Media New York 2013

\begin{abstract}
The vibrating-wire viscometer has proven to be an exceedingly effective means of determining the viscosity of liquids over a wide range of temperature and pressure. The instrument has a long history but a variety of technological and theoretical developments over a number of years have improved its precision and most recently have enabled absolute measurements of high accuracy. However, the nature of the electrical measurements required for the technique has inhibited its widespread use for electrically conducting liquids so that there have been only a limited number of measurements. In the particular context of ionic liquids, which have themselves attracted considerable attention, this is unfortunate because it has meant that one primary measurement technique has seldom been employed for studies of their viscosity. In the last 2 years systematic efforts have been made to explore the applicability of the vibrating-wire technique by examining a number of liquids of increasing electrical conductivity. These extensions have been successful. However, in the process we have had cause to review previous studies of the viscosity and density of the same liquids at moderate temperatures and pressures and significant evidence has been accumulated to cause concern about the application of a range of viscometric techniques to these particular fluids. Because the situation is reminiscent of that encountered for a new set of environmentally friendly refrigerants at the end of the last decade, in this paper the experimental methods employed with these liquids have been reviewed which leads to recommendations for the handling of these materials that may have
\end{abstract}

J. C. F. Diogo · F. J. P. Caetano · J. M. N. A. Fareleira · W. A. Wakeham (凶)

Centro de Química Estrutural, Instituto Superior Técnico,

Universidade Técnica de Lisboa, Av. Rovisco Pais, 1049-001 Lisbon, Portugal

e-mail:w.a.wakeham@soton.ac.uk

F. J. P. Caetano

Universidade Aberta, R. da Escola Politécnica, 147, 1269-001 Lisbon, Portugal 
consequences beyond viscometric measurements. In the process new viscosity and density data for 1-hexyl-3-methylimidazolium bis[(trifluoromethyl)sulfonyl]imide $\left[\mathrm{C}_{6} \mathrm{mim}\right]\left[\mathrm{NTf}_{2}\right]$, 1-ethyl-3-methylimidazolium ethyl sulfate $\left[\mathrm{C}_{2} \mathrm{mim}\right]\left[\mathrm{EtSO}_{4}\right]$, and 1-ethyl-3-methylpyridinium ethyl sulfate $\left[\mathrm{C}_{2} \mathrm{mpy}\right]\left[\mathrm{EtSO}_{4}\right]$ have been obtained.

Keywords 1-Ethyl-3-methylpyridinium ethyl sulfate $\left[\mathrm{C}_{2} \mathrm{mim}\right]\left[\mathrm{EtSO}_{4}\right]$. 1-Ethyl-3-methylpyridinium ethyl sulfate $\left[\mathrm{C}_{2} \mathrm{mpy}\right]\left[\mathrm{EtSO}_{4}\right]$.

1-Hexyl-3-methylimidazolium bis[(trifluoromethyl)sulfonyl]imide[ $\mathrm{C}_{6}$ mim] $\left[\mathrm{NTf}_{2}\right]$. Ionic liquids · Viscosity

\section{Introduction}

On several occasions in the last 50 years the science of viscometry has come under close scrutiny because of revelations of inadequacies in the application of classical methods of measurements to new circumstances or to fluids that have seldom been studied before. In the late 1960s there was an accumulating body of evidence from studies of the intermolecular forces of simple atomic gases [1], by molecular beam techniques and infrared spectroscopy, that the previous measurements of the viscosity of gases at atmospheric pressure and at low and high temperatures were in substantial error. These observations prompted much more careful development of the theory and practice of viscometers using more complete fluid mechanical analyses than had been conducted hitherto [2].

The second example of a similar problem arose when the Montreal Protocol on refrigerants harmful to the ozone layer [3-5] stimulated the search for and production of a number of alternative refrigerants to replace those considered harmful. That stimulation drove a need for the measurement of the thermodynamic and transport properties of the fluids for both the design of production facilities and for assessment of the process of substitution in applications. The task attracted many laboratories and workers who had not been traditionally engaged in viscosity measurements, and a vast array of results emerged rapidly. In the absence of reliable existing data, there was apparently no way to verify the output of this outpouring of new viscosity data. As a consequence, it was only some time later that many of these sets of early, hurried measurements were shown to be in error by an international study. The study was organized by the IUPAC Subcommittee on Transport Properties (now the International Association for Transport Properties), on one particular refrigerant (R134a) [6]. Hindsight revealed that the early studies had forgotten (or disregarded) the accumulated wisdom of careful practitioners of viscometry, including the need to have exact working equations for instruments and uncontaminated samples. Again the science of viscometry suffered some reputational damage.

In the last decade there have emerged another new class of liquids, known as ionic liquids [7], or room temperature ionic liquids (RTILs) for which very little data on thermophysical properties initially existed but for which the data rapidly become necessary as applications associated with 'greener' chemical routes to products have been in greater demand. A number of earlier papers have highlighted the need for care in the measurement of the properties of these new fluids [8-10] and yet there 
is already sufficient evidence to suggest that history is being repeated at least with respect to viscometry. There are very considerable differences emerging between the results reported by various workers on the viscosity of some of these ionic liquids that are large enough to cause grave concern that the subject of viscometry could yet again fall into disrepute.

This paper examines some of those discrepancies, attributes them to several possible causes, and illustrates how proper checks can be made to ensure that the experimental methods being used are properly understood. Clear recommendations are made to authors and journal editors about how to avoid repeating the mistakes of the past. In the context of the widespread interest in thermophysical property measurements of complex fluids, the overarching lesson is that it is necessary to assure an accuracy fit for the purpose for which the data are required [11].

\section{Evidence Surrounding Ionic Liquids}

The viscosity of RTILs such as $\left[\mathrm{C}_{2} \mathrm{mim}\right]\left[\mathrm{EtSO}_{4}\right]$ or $\left[\mathrm{C}_{2} \mathrm{mpy}\right]\left[\mathrm{EtSO}_{4}\right]$, has been studied since the first interest in these fluids [12] was generated by virtue of their potential as "green" solvents. Almost immediately discrepancies between the results of various authors began to emerge [7]. Indeed the situation was observed to be poor for a number of thermophysical and electrical properties, although for viscosity and electrical conductivity it was perhaps worst of all [7].

Tables 1 and 2 give a list of the viscosity measurements conducted on one particular liquid, $\left[\mathrm{C}_{6} \mathrm{mim}\right]\left[\mathrm{NTf}_{2}\right]$, chosen for reasons that will be explained later. The list includes several sets of early measurements [13-18], and the results of a round-robin IUPAC study [8,9,19-21]. In Ref. [22] we report viscosity data of three ionic liquids, including $\left[\mathrm{C}_{6} \mathrm{mim}\right]\left[\mathrm{NTf}_{2}\right]$. Tables 1 and 2 are a reproduction of Tables $6 \mathrm{a}$ and $\mathrm{b}$ of Ref. [22] and are shown here in order to aid the readers. The table shows that a wide variety of different techniques have been used and also that the purity of the sample, particularly with respect to water content, receives variable attention. If the results of the complete set of early, non-IUPAC, measurements [13-18], indicated in Table 1, on the same liquid are examined, as is done in Fig. 1, discrepancies from a later correlation approved by IUPAC are very large (and in both directions), reaching as much as $-16 \%$, despite claims of uncertainties of $2 \%$ or $3 \%$ for the results of individual authors.

A similar situation arose for other ionic liquids and prompted rapid international action under the auspices of the International Union of Pure and Applied Chemistry (IUPAC), which launched a study Project (2002-005-1-100) to establish agreed and standard values of the thermophysical properties of one particular ionic liquid, $\left[\mathrm{C}_{6} \mathrm{mim}\right]\left[\mathrm{NTf}_{2}\right]$. This liquid was therefore chosen to be representative of the entire class of RTILs. Marsh et al. [8] detail the reasons for the selection of $\left[\mathrm{C}_{6}\right.$ mim] $\left[\mathrm{NTf}_{2}\right.$ ] for the reference fluid. Essentially they are a balance between disparate factors and recognition that it is stable, has a low viscosity and low water solubility, and is easily prepared and purified.

As a part of the IUPAC project, a number of laboratories throughout the world were commissioned to perform measurements of a number of properties on samples of the 


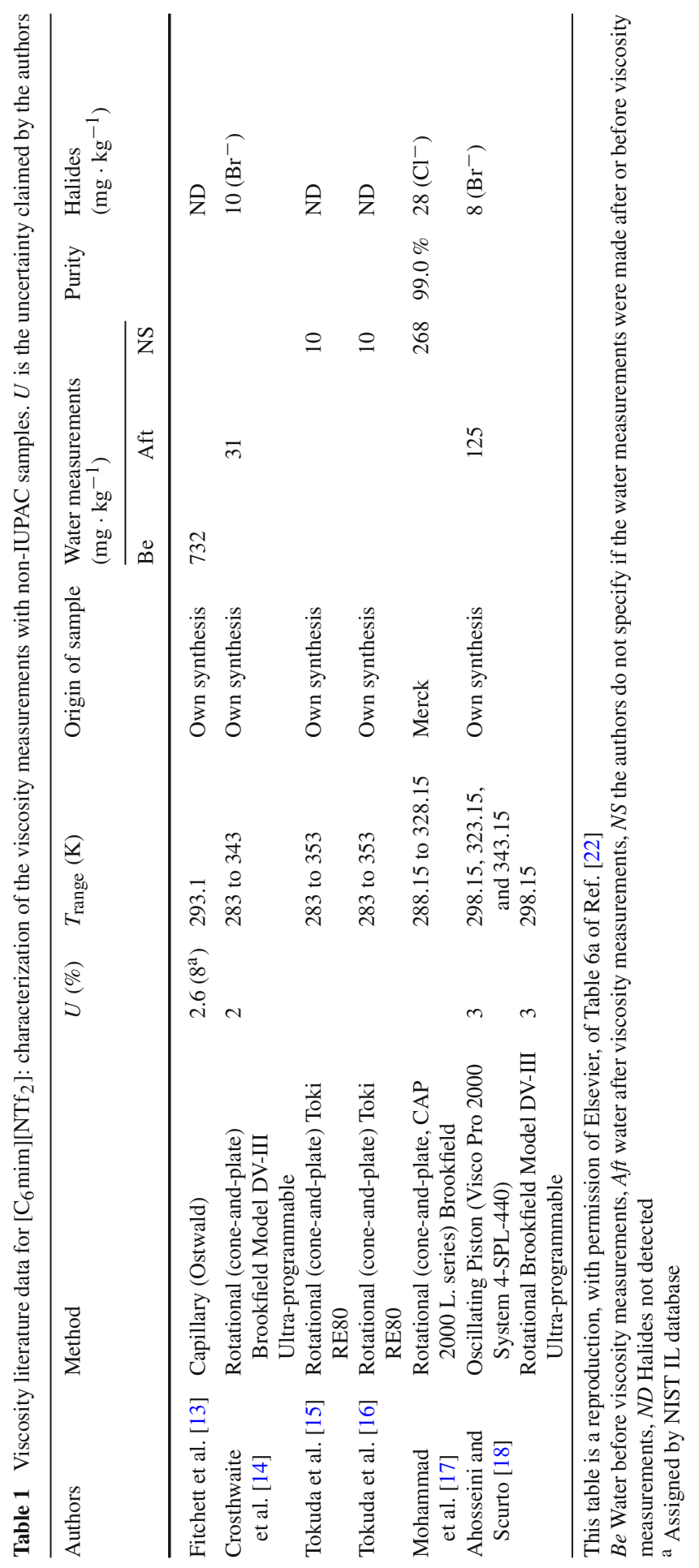




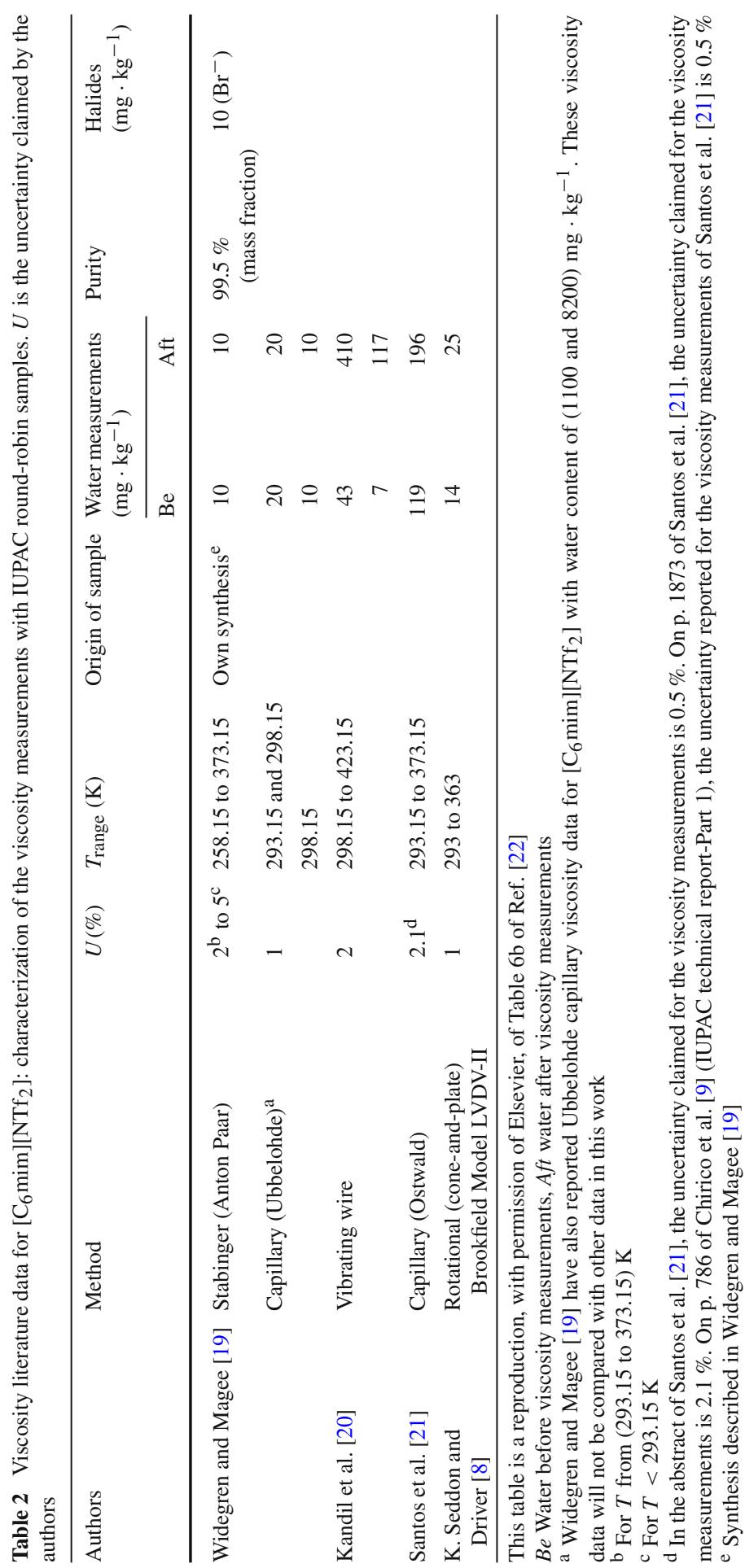




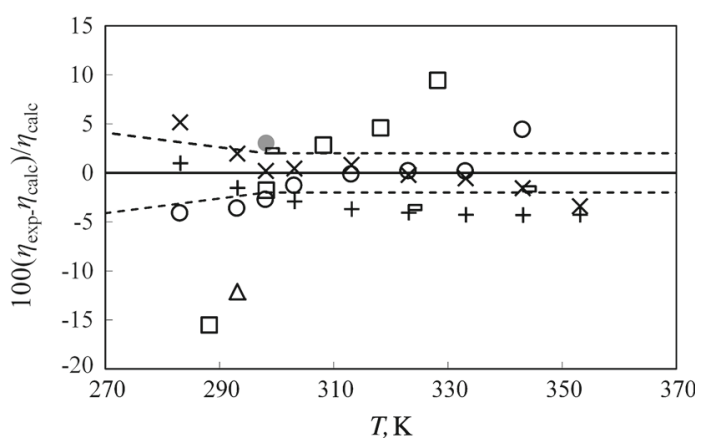

Fig. 1 Deviations from the correlation of Eq. 4 from Chirico et al. [9] obtained with the round-robin viscosity data of the IUPAC sample of $\left[\mathrm{C}_{6}\right.$ mim] $\left[\mathrm{NTf}_{2}\right]$. Non-IUPAC samples: Fichett et al. [13], $\Delta$, Capillary Zeitfuchs cross-arm; Crosthwaite et al. [14], $\bigcirc$, cone-and-plate; Tokuda et al. [15], +, cone-and-plate; Tokuda et al. [16], $\times$, cone-and-plate; Muhammad et al. [17], $\square$, cone-and-plate; Ahosseini and Scurto [18], $\square$, oscillating piston; $\mathcal{O}$, cone-and-plate

liquid drawn from a common supply and it was agreed to monitor the water content of the samples as a part of the work. This round-robin project was built upon many examples of similar activities conducted by international bodies, and it was expected that the application of different experimental methods to the measurement of the properties of a sample, handled through agreed protocols, would lead to close agreement among the results. This would make the establishment of agreed values straightforward. The results of this round-robin study for all properties were summarized in 2009 by Marsh et al. [8] and by Chirico et al. [9].

Figure 2 compares the various results obtained for the round-robin sample in the IUPAC project, as indicated in Table 2, with a correlation of all except one set of those data developed in the same work. It is this correlation that was also used in Fig. 1. Deviations of up to $16 \%$ can still be observed. The large deviations arise from work with the cone-and-plate viscometer, where the uncertainty of the data was claimed to be $1 \%$ [8]. These were the only data not actually used in the correlation. Some attention was also given to the study of the effect of water on the viscosity of the sample. It is possible to discern from Figs. 1 and 2 and Tables 1 and 2 that the water content of the samples has a significant effect on the reported viscosity at least comparable with the claimed uncertainties. The study revealed that, with appropriate care, tolerable agreement could be obtained for the viscosity of these liquids. However, at the same time it demonstrated how considerable errors could also arise. The combined, expanded uncertainty assigned for the IUPAC viscosity correlation is $2 \%$ for $(298.15 \leq T \leq 370) \mathrm{K}$ and increases linearly up to $5 \%$ from (298.15 to 258 ) $\mathrm{K}$ and from ( 370 to 433 ) K. However, the results that individual authors reported have a variation from $-2.0 \%$ to $+3.3 \%$ from the correlation even in the range of (298.15 to 330) K.

It would not be unreasonable at this point for a dispassionate external observer to ask: How can it be that in the twenty-first century the claims of uncertainty for viscosity data are greatly exceeded by the differences between the results, obtained with essentially the same sample? 


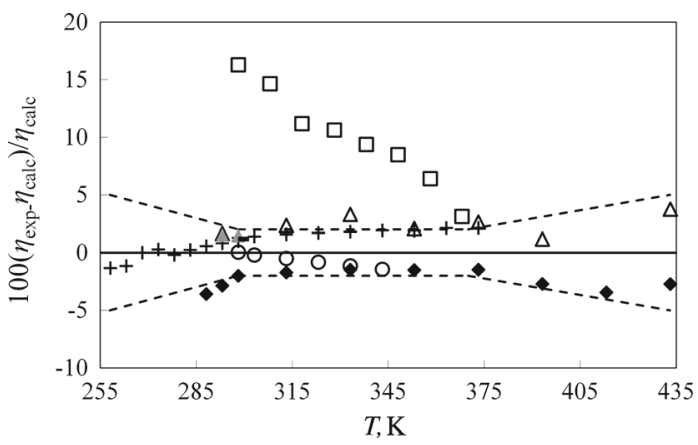

Fig. 2 Deviations from the correlation of Eq. 4 from Chirico et al. [9] obtained with the round-robin viscosity data of the IUPAC sample of $\left[\mathrm{C}_{6} \mathrm{mim}\right]\left[\mathrm{NTf}_{2}\right]$ (Chirico et al. [9]). IUPAC round-robin: Widegren and Magee [19], + , Stabinger, $w_{\mathrm{H}_{2} \mathrm{O}}$ from (10 to 10) $\mathrm{mg} \cdot \mathrm{kg}^{-1}$; idem, $\Delta$, Ubbelohde capillary, $w_{\mathrm{H}_{2} \mathrm{O}}$ from (20 to 20) $\mathrm{mg} \cdot \mathrm{kg}^{-1}$; ibidem, $\boldsymbol{\square}$, Ubbelohde capillary, $w_{\mathrm{H}_{2} \mathrm{O}}$ from (10 to 10$) \mathrm{mg} \cdot \mathrm{kg}^{-1}$; Kandil et al. [20], $\diamond$, sample A, $w_{\mathrm{H}_{2} \mathrm{O}}$ from (43 to 410$) \mathrm{mg} \cdot \mathrm{kg}^{-1}$; idem, $\Delta$ sample B, vibrating wire, $w_{\mathrm{H}_{2} \mathrm{O}}$ from (7 to 117) $\mathrm{mg} \cdot \mathrm{kg}^{-1}$; Santos et al. [21], $\bigcirc$, Ostwald capillary, $w_{\mathrm{H}_{2} \mathrm{O}}$ from (119 to 196) $\mathrm{mg} \cdot \mathrm{kg}^{-1}$; Seddon and Driver in Marsh et al. [8], $\square$, cone-and-plate, $w_{\mathrm{H}_{2} \mathrm{O}}$ from (14 to 25$) \mathrm{mg} \cdot \mathrm{kg}^{-1}$

\section{Possible Explanations for the Discrepancies}

In order to safeguard the reputation of the science of viscometry, it seems essential to understand the origin of all of the observed discrepancies. There seem to be two avenues to explore why these discrepancies should arise. The first group is related to the techniques of measurement and the second with the particular nature of ionic liquids.

\subsection{Experimental Techniques}

The first observation to make is one that affects all techniques. Few viscometers are operated in an absolute mode because of the difficulty of having a sufficiently accurate knowledge of the dimensions of some part of the viscometer. As a result, it is usual to calibrate a viscometer with one or more fluids whose viscosity is known. There are a number of liquids whose viscosity is known quite well and for which the uncertainty in the standard viscosity is also known, but only for water does that uncertainty approach a few parts in one thousand [23]; typically the uncertainty is much larger. Necessarily, the uncertainty in the viscosity of the calibrant must contribute to the uncertainty in the final value of the test liquid. It is not always clear that this calibration error has been added to a statistical analysis of the experimental error; very often the quoted uncertainty is actually a measure simply of repeatability, disregarding systematic errors, for instance, owing to the assigned measurement temperature.

The second, quite general point is that calibration cannot offset an incomplete understanding of the fluid mechanics and operation of a viscometer. Calibration can only be used to determine parameters of an instrument that is well characterized and for which an exact working equation exists. Again this condition seems quite often to 
be ignored in even recent viscometric measurements. Property measuring instruments must have a complete set of working equations. Many instruments used abundantly for the measurement of viscosity of ionic liquids are based solely on empirical calibrations, because there are no models that can describe sufficiently well the fluid mechanics involved in their operation.

With respect to particular viscometers, we can offer a number of observations about those instruments that have been applied to measurements on RTILs.

For capillary viscometers there is an entirely adequate working equation for the main fluid flow [24], but there are a number of corrections to it for practical application that must be made in work of the highest quality [24]. One effect often not dealt with is that caused by the surface tension of the liquid which influences the flow in suspended level capillary viscometers [25]. This effect has seldom been considered explicitly because it is argued to be a small effect which can be neglected when the surface tension of the test liquid differs rather little from that of the calibrant liquid [26]. In fact, the effect is small only for capillary viscometers known as master viscometers which employ a large hydrostatic head. These devices have not been the viscometers employed for ionic liquids. It should further be noted that for ionic liquids the surface tension (actually more correctly the ratio of surface tension to density $(\sigma / \rho)$ ) often departs dramatically from that of the fluids that have more traditionally been studied and which form the set of calibrant fluids typically employed. Thus, the effect for ionic liquids has generally been large, uncorrected, and unconsidered.

Cone-and-plate viscometers were originally conceived as devices for the study of the rheology of non-Newtonian fluids. They are not strictly intended for viscometric results of the highest accuracy, mainly because the usual working equation for the instrument is not exact and the corrections are not known. Furthermore, the water content of the sample studied must change with time if the device is operated in air, and even if operated in a closed atmosphere, the gas inevitably surrounding the fluid will be dissolved in it.

The Anton Paar Stabinger SVM 3000 viscometer uses a rotating cylindrical tube containing the liquid sample and a coaxial, freely floating inner rotor [27-29]. The outer tube is rotated at a constant angular velocity and the inner rotor then rotates at a constant angular velocity because of the viscous force upon it. The velocity of the rotating cylinder is measured by means of observing the rotation of a magnet that is embedded within it. The device has proved quite successful for fluids that are not electrically conducting, and so its application to the new problem of ionic liquids was natural. However, to the authors' knowledge there has been no study of the effect of electromagnetic phenomena in the case when an electrically conducting liquid fills the annulus between the rotating tube and the inner rotor. At the very least, one could expect an investigation to demonstrate that the effect is negligible or non-existent. Its absence leaves unanswered questions about the validity of the method.

\subsection{Ionic Liquids Themselves}

Perhaps the greatest issue that has bedeviled the measurement of the viscosity of ionic liquids has been that of sample purity. The synthesis of these samples of ionic liquids necessarily involves the use of solvents and their complete removal after synthesis 
is clearly an essential condition of preparation. Secondly, the liquids dissolve water readily from the atmosphere so that it is essential to measure the water content of the sample before and after measurement, as well as taking due care to avoid contamination during measurement by means of isolation from water-containing atmospheres. Finally, it has been observed that halide salts in the sample [30] have a profound effect upon the viscosity and their levels need to be reduced to the lowest possible levels and recorded.

Unfortunately, it has been rather too common practice that authors have not monitored water levels before and after measurement. More usually, either only one water content value has been stated with a comment that there was no significant variation or there is simply no mention of when the water content was determined. Nieto de Castro [7] notes in his study of this problem "However, the pressure to publish new data masked the difficulties in obtaining samples of high purity, and less care in the handling of those samples."

The water content in the samples of ionic liquids affects significantly their viscosity as is illustrated in Fig. 3. This figure shows the deviations of selected data sets for the viscosity of $\left[\mathrm{C}_{6} \mathrm{mim}\right]\left[\mathrm{NTf}_{2}\right]$, characterized by a limited water contamination (less than $120 \mathrm{mg} \cdot \mathrm{kg}^{-1}$ ), monitored both before and after the viscosity measurements, from the correlation published by the IUPAC project [9]. Those selected data include two sets used to develop the IUPAC correlation [9], obtained, namely, by Widegren and Magee [19] and by Kandil et al. [20], and our own set of vibrating-wire results (characterized in Table 3), published in Ref. [22]. It is important to note that the mentioned correlation [9] was built using viscosity data obtained with samples for which the complete water contents ranged from (10 to 410) $\mathrm{mg} \cdot \mathrm{kg}^{-1}$. It is clear that all the data from the selected sources in Fig. 3 lie above the IUPAC correlation. The minimum and maximum deviations from the correlation are $(-1.1$ to +3.7$) \%$, respectively. However, in the range from (263.15 to 433.15$) \mathrm{K}$, all the data sets agree very well

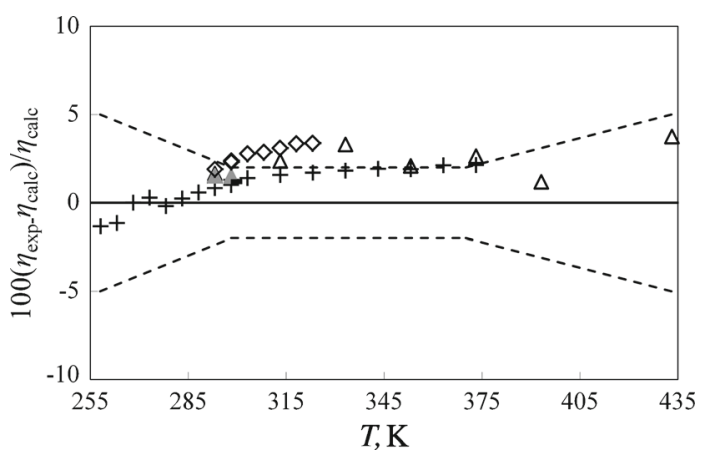

Fig. 3 Deviations of selected data sets for the viscosity of $\left[\mathrm{C}_{6} \mathrm{mim}\right]\left[\mathrm{NTf}_{2}\right]$ from the correlation of Eq. 4 of Ref. [9]. The selected data sets are characterized by having a reported water content, before and after viscosity measurements, lower than $120 \mathrm{mg} \cdot \mathrm{kg}^{-1}$, and were obtained either in the round-robin promoted

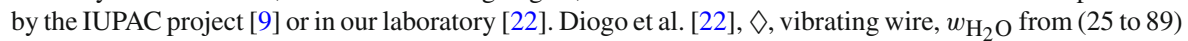
$\mathrm{mg} \cdot \mathrm{kg}^{-1}$. IUPAC round-robin: Widegren and Magee [19], +, Stabinger, $w_{\mathrm{H}_{2} \mathrm{O}}$ from (10 to 10$) \mathrm{mg} \cdot \mathrm{kg}^{-1}$; idem, $\Delta$, Ubbelohde capillary, $w_{\mathrm{H}_{2} \mathrm{O}}$ from (20 to 20$) \mathrm{mg} \cdot \mathrm{kg}^{-1}$; ibidem, $\boldsymbol{\square}$, Ubbelohde capillary, $w_{\mathrm{H}_{2} \mathrm{O}}$ from (10 to 10$) \mathrm{mg} \cdot \mathrm{kg}^{-1}$; Kandil et al. [20], $\Delta$, sample B, vibrating wire, $w_{\mathrm{H}_{2} \mathrm{O}}$ from (7 to 117$) \mathrm{mg} \cdot \mathrm{kg}^{-1}$ 
Table 3 Characterization of the viscosity measurements of $\left[\mathrm{C}_{6} \mathrm{mim}\right]\left[\mathrm{NTf}_{2}\right]$ performed by our group in Ref. [22]

\begin{tabular}{|c|c|c|c|c|c|c|c|c|}
\hline \multirow[t]{2}{*}{ Authors } & \multirow[t]{2}{*}{ Method } & \multirow[t]{2}{*}{$\begin{array}{l}U \\
(\%)\end{array}$} & \multirow[t]{2}{*}{$\begin{array}{l}T_{\text {range }} \\
(\mathrm{K})\end{array}$} & \multirow[t]{2}{*}{$\begin{array}{l}\text { Origin of } \\
\text { sample }\end{array}$} & \multicolumn{2}{|c|}{$\begin{array}{l}\text { Water measurements } \\
\left(\mathrm{mg} \cdot \mathrm{kg}^{-1}\right)\end{array}$} & \multirow[t]{2}{*}{ Purity } & \multirow[t]{2}{*}{$\begin{array}{l}\text { Halides } \\
\left(\mathrm{mg} \cdot \mathrm{kg}^{-1}\right)\end{array}$} \\
\hline & & & & & $\mathrm{Be}$ & Aft & & \\
\hline $\begin{array}{l}\text { Diogo } \\
\quad \text { et al. [22] }\end{array}$ & $\begin{array}{l}\text { Vibrating } \\
\text { wire }\end{array}$ & 2 & 293 to 323 & IoLiTec & 25 & 89 & $\begin{array}{l}99 \% \text { (mass } \\
\text { fraction) }\end{array}$ & 100 \\
\hline
\end{tabular}

$U$ is the uncertainty claimed by the author

$B e$ Water before viscosity measurements, Aft water after viscosity measurements

with each other. These comparisons therefore suggest that the IUPAC correlation has been biased by the results obtained with samples whose water content, at least after measurements, was greater than $120 \mathrm{mg} \cdot \mathrm{kg}^{-1}$.

A comparison of the viscosity, measured by the vibrating-wire technique, of two $\left[\mathrm{C}_{2} \mathrm{mim}\right]\left[\mathrm{EtSO}_{4}\right]$ samples, with different water contents, that illustrates the importance of this contamination is also presented later in Sect. 4.

It is also worth noting here that ionic liquids pose other challenges for measurement because they may be degraded by the action of hydrolysis or thermal degradation. There may also arise problems with corrosion in some viscometers. Furthermore, they are electrically conducting and finally the range of viscosity they exhibit is very large.

\subsection{Commentary on Measurements to Date}

In view of the observations made here and elsewhere [7] about the measurement of the viscosity of ionic liquids, it seems appropriate to make some comments intended to improve the situation especially when commercial instruments are employed.

A wide divergence of practice when stating the uncertainty of viscosity measurements seems to have developed. For example, some authors claim an uncertainty for capillary measurements equal to the commercial manufacturer's statement of the uncertainty in the calibration constant and others claim an uncertainty equal to repeatability. It must be stressed that the use of a commercial instrument does not absolve an author from the responsibility to use standard methodology for estimating uncertainties.

Many commercial viscometers are not supplied by the manufacturer with special systems to avoid water contamination whether these are capillary viscometers, rotational viscometers, oscillating-body viscometers, or falling body viscometers. In this case authors must develop special techniques to prevent water contamination; this seldom seems to be the case.

Many authors estimate the uncertainty in their results for ionic liquids to be lower than $1 \%$ and some even as low as $0.5 \%$. These values would seem to be a gross underestimate given the uncertainty in any likely calibrant viscosity and the inadequate precautions taken to safeguard samples. Nieto de Castro et al. [10] have recommended the use only of primary viscometric techniques for use with ionic liquids which they identified as oscillating-body viscometers, the torsional oscillating quartz crystal, and 
the vibrating-wire viscometer. Those authors have argued that with these methods uncertainties of about $2 \%$ can be achieved provided that due care is taken with regard to calibration, sample handling, thermometer calibration, surface tension, and treatment of any other systematic errors.

In what follows we indicate some of the steps that must be taken to achieve this aim with respect to a vibrating-wire viscometer and the capillary viscometer.

\section{Vibrating-Wire Viscometer}

The viscosity of two samples of 1-ethyl-3-methylimidazolium ethyl sulfate [ $\left.\mathrm{C}_{2} \mathrm{mim}\right]$ $\left[\mathrm{EtSO}_{4}\right]$, with different water content, were compared in this work. Sample A, of $\left[\mathrm{C}_{2} \mathrm{mim}\right]\left[\mathrm{EtSO}_{4}\right]$ was provided for the present work under Project (PTDC/QUI/66826/ 2006). The sample was prepared free of halides, by the group of Afonso at CQFMCentro de Química-Física Molecular and IN-Institute of Nanosciences and Nanotechnology, Instituto Superior Técnico, Universidade Técnica de Lisboa, Portugal. The procedures for its preparation and the characterization of its chemical purity are fully described by Nieto de Castro et al. [31]. Its viscosity was measured in the present work, using the vibrating-wire technique. Sample B is characterized in Ref. [22], where the results for both its viscosity, measured with the vibrating-wire technique, and density, measured with an Anton Paar DMA 5000 densimeter, are presented. The handling of the IL samples was described in Ref. [22]. The water content of sample $\mathbf{B}$, before and after the viscosity measurements, was only (6 to 7) $\mathrm{mg} \cdot \mathrm{kg}^{-1}$ [22]. For sample A the water content was, before and after viscosity measurements, (149 and 231) $\mathrm{mg} \cdot \mathrm{kg}^{-1}$.

We have described our vibrating-wire viscometer as it has been used for ionic liquids with viscosities up to $500 \mathrm{mPa} \cdot \mathrm{s}$ elsewhere [32,33]. Briefly, it consists of a $200 \mu \mathrm{m}$ diameter wire with a vibrational frequency of about $1 \mathrm{kHz}$. In order to obtain the viscosity by the vibrating-wire technique, the density is needed [34]. The density of sample A of $\left[\mathrm{C}_{2} \mathrm{mim}\right]\left[\mathrm{EtSO}_{4}\right]$ was obtained with an Anton Paar DMA 5000 densimeter according to the procedure previously described by Diogo et al. [33]. The expanded uncertainty, $U(\rho)$, estimated for these density data is $0.1 \%$, at a $95 \%$ confidence level, based on a previous study [33]. The experimental density results for sample A of $\left[\mathrm{C}_{2} \mathrm{mim}\right]\left[\mathrm{EtSO}_{4}\right]$ obtained in this work are presented in Table 4; they are ordered in the same sequence as the measurements were made.

The density data in Table 4 were correlated as a function of temperature by an equation of the form,

$$
\rho(T)=l+m T+n T^{2}
$$

The parameters of Eq. 1 are shown in Table 5, together with the relative root mean square deviation, rmsd, and the bias of the data, defined as

$$
\operatorname{rmsd}=\left[\frac{1}{N} \sum_{i}^{N}\left(\frac{Z_{\text {exp }, i}}{Z_{\text {corr }, i}}-1\right)^{2}\right]^{1 / 2}
$$


Table 4 Density measurements of sample $\mathbf{A}$ of $\left[\mathrm{C}_{2} \mathrm{mim}\right]\left[\mathrm{EtSO}_{4}\right]$ as a function of temperature and at atmospheric pressure

\begin{tabular}{llllll}
\hline$T(\mathrm{~K})$ & $\rho\left(\mathrm{kg} \cdot \mathrm{m}^{-3}\right)$ & $T(\mathrm{~K})$ & $\rho\left(\mathrm{kg} \cdot \mathrm{m}^{-3}\right)$ & $T(\mathrm{~K})$ & $\rho\left(\mathrm{kg} \cdot \mathrm{m}^{-3}\right)$ \\
\hline 298.15 & 1238.14 & 320.65 & 1222.96 & 290.66 & 1243.24 \\
300.65 & 1236.44 & 318.15 & 1224.63 & 293.15 & 1241.55 \\
303.15 & 1234.75 & 315.66 & 1226.31 & 295.65 & 1239.85 \\
305.64 & 1233.06 & 313.15 & 1228.00 & 298.15 & 1238.15 \\
308.15 & 1231.37 & 310.66 & 1229.68 & 300.65 & 1236.46 \\
310.64 & 1229.69 & 308.16 & 1231.37 & 303.15 & 1234.76 \\
313.15 & 1228.00 & 305.66 & 1233.06 & 305.65 & 1233.06 \\
318.15 & 1224.64 & 303.15 & 1234.75 & 308.14 & 1231.37 \\
320.65 & 1222.96 & 300.66 & 1236.45 & 310.64 & 1229.68 \\
& & 298.16 & 1238.15 & 313.15 & 1228.00 \\
& & 295.65 & 1239.85 & 315.64 & 1226.32 \\
& & 293.16 & 1241.54 & 318.15 & 1224.64 \\
& & 290.65 & 1243.24 & 320.65 & 1222.96 \\
\hline
\end{tabular}

Measured water content was between (74 and 388) $\mathrm{mg} \cdot \mathrm{kg}^{-1}$ before and after the measurements, respectively. The estimated combined expanded uncertainties at a $95 \%$ confidence level are $U(T)=0.05 \mathrm{~K}$ and $U(\rho)=0.1 \%$

Note: Density data of sample B were reported in Ref. [22]

Table 5 Parameters of Eq. 1 for the experimental density measurements of sample $\mathbf{A}$ of $\left[\mathrm{C}_{2} \mathrm{mim}\right]\left[\mathrm{EtSO}_{4}\right]$ shown in Table 4 and the corresponding rmsd and bias of the density data from the fit

\begin{tabular}{ll}
\hline$l\left(\mathrm{~kg} \cdot \mathrm{m}^{-3}\right)$ & 1456.24 \\
$m\left(\mathrm{~kg} \cdot \mathrm{m}^{-3} \cdot \mathrm{K}^{-1}\right)$ & -0.78408 \\
$n\left(\mathrm{~kg} \cdot \mathrm{m}^{-3} \cdot \mathrm{K}^{-2}\right)$ & $1.763 \times 10^{-4}$ \\
$\operatorname{rmsd}(\%)$ & $4.01 \times 10^{-4}$ \\
bias $(\%)$ & $-1.15 \times 10^{-5}$ \\
\hline
\end{tabular}

Note: The fitting parameters of Eq. 1 for sample B were reported in Ref. [22]

$$
\text { bias }=\frac{1}{N} \sum_{i}^{N}\left(\frac{Z_{\mathrm{exp}, i}}{Z_{\mathrm{corr}, i}}-1\right)
$$

The results for the viscosity of sample $\mathbf{A}$ of $\left[\mathrm{C}_{2} \mathrm{mim}\right]\left[\mathrm{EtSO}_{4}\right]$ obtained using the vibrating wire are shown in Table 6 . For each measurement the temperature variation was less than $0.005 \mathrm{~K}$. For each temperature, $T$, the viscosity, $\eta$, is the mean value of, at least, 5 measurements and all of them differing less than $0.01 \mathrm{~K}$ from the mean temperature. The standard deviation of the mean values of the viscosity was less than $0.04 \%$ for all temperatures. For each temperature, the density, $\rho$, is given in the second column. These were calculated by the correlation of Eq. 1, with the parameters presented in Table 5.

The vibrating-wire viscometer was used unchanged to determine the viscosity of the two samples of $\left[\mathrm{C}_{2} \mathrm{mim}\right]\left[\mathrm{EtSO}_{4}\right]$. Figure 4 shows the two sets of results. The baseline 
Table 6 Experimental results for the viscosity, $\eta$, of sample $\mathbf{A}$ of $\left[\mathrm{C}_{2} \mathrm{mim}\right]\left[\mathrm{EtSO}_{4}\right]$, measured in the present work with the vibrating-wire technique at temperatures, $T$, and at a pressure of $0.1 \mathrm{MPa}$

\begin{tabular}{clc}
\hline$T(\mathrm{~K})$ & $\rho\left(\mathrm{kg} \cdot \mathrm{m}^{-3}\right)$ & $\eta(\mathrm{mPa} \cdot \mathrm{s})$ \\
\hline 293.14 & 1241.6 & 125.7 \\
298.19 & 1238.1 & 97.19 \\
303.15 & 1234.8 & 76.80 \\
308.21 & 1231.3 & 61.42 \\
313.14 & 1228.0 & 50.05 \\
318.13 & 1224.7 & 41.42 \\
\hline
\end{tabular}

Density values at nominal temperatures, $\rho(T)$, were obtained from Eq. 1, with parameters from Table 5 . Measured water content before and after the measurements of sample $\mathbf{A}$ of $\left[\mathrm{C}_{2} \mathrm{mim}\right]\left[\mathrm{EtSO}_{4}\right]$ : (149 and 231) $\mathrm{mg} \cdot \mathrm{kg}^{-1}$. The estimated combined expanded uncertainties at a $95 \%$ confidence level are $U(T)=$ $0.05 \mathrm{~K}, U(\rho)=0.1 \%$, and $U(\eta)=2 \%$

Fig. 4 Deviations from the correlation of the viscosity results for $\left[\mathrm{C}_{2} \mathrm{mim}\right]\left[\mathrm{EtSO}_{4}\right]$ sample B, published in Ref. [22]: Diogo et al. [22], $\diamond, w_{\mathrm{H}_{2} \mathrm{O}}$ from (6 to 7) $\mathrm{mg} \cdot \mathrm{kg}^{-1}$; present work, sample $\mathbf{A}, \bigcirc, w_{\mathrm{H}_{2} \mathrm{O}}$ from (149 to 231 ) $\mathrm{mg} \cdot \mathrm{kg}^{-1}$ (data from Table 6)

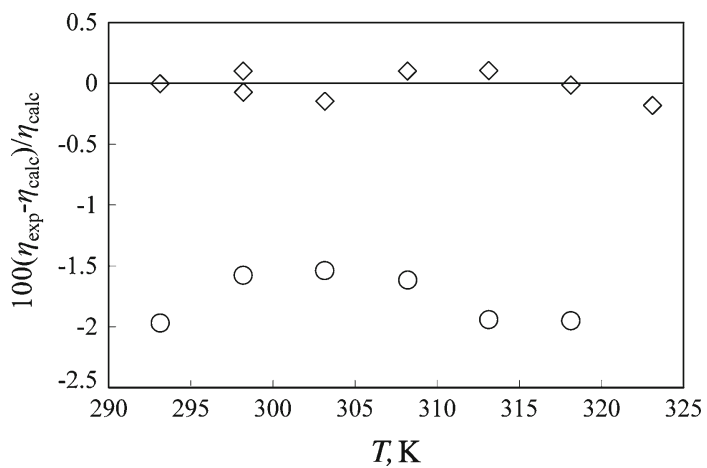

of the deviation plot is a correlation of the results for sample $\mathbf{B}$ [22]. It can be seen that the differences between the viscosities of the two samples, unequivocally attributable to the impurity content, amount to about $2 \%$. The most relevant impurities present in the samples are water and halides. The estimated expanded uncertainty, $U(\eta)$, at a $95 \%$ confidence level, of this implementation of the vibrating-wire techniques is one of $2 \%$, when the error of calibration is included, whereas the reproducibility and repeatability are about $0.5 \%$. It follows that the level of impurities in a sample of an ionic liquid must be within the range of the samples studied here if an expanded uncertainty (at a $95 \%$ confidence level) even approaching $2 \%$ is to be claimed.

In the vibrating-wire technique the wire is excited into movement by a sinusoidal electrical current in the wire contained in a magnetic field. With an electrically insulating liquid both this and the subsequent electromagnetic detection of the motion of the wire immersed in the fluid is straightforward [32,35]. However, when the fluid to be studied is electrically conducting, it is not obvious that the situation is still the same, since the conductivity of the liquid may play a role. Perhaps for this reason there have been few measurements so far of the viscosity of ionic liquids using this technique [21,22,33] despite the recommendation of Nieto de Castro et al. [10]. 
To examine whether the technique might be applied to ionic liquids with a modest electrical conductivity $\left(0.0394 \mathrm{~S} \cdot \mathrm{m}^{-1}\right.$ at $50{ }^{\circ} \mathrm{C}$, according to [36]) we have studied the behavior of a vibrating-wire viscometer with trihexyl(tetradecyl)phosphonium dicyanamide $\left[\mathrm{P}_{6,6,6,14}\right][\mathrm{dca}]$ [33]. It was concluded that the effect of the electrical conductivity on the performance of the viscometer was negligible. However, the conductivity of many RTILs is much higher. For reference it is perhaps useful to state that the electrical conductivity of $\left[\mathrm{C}_{2} \mathrm{mim}\right]\left[\mathrm{EtSO}_{4}\right]$ is $0.9605 \mathrm{~S} \cdot \mathrm{m}^{-1}$ at $50{ }^{\circ} \mathrm{C}$, according to Ref. [37], while at the same temperature that of a $0.01 \mathrm{M}$ aqueous solution of $\mathrm{KCl}$ is $0.141 \mathrm{~S} \cdot \mathrm{m}^{-1}$ [38] and that of a $0.1 \mathrm{M}$ solution is $1.29 \mathrm{~S} \cdot \mathrm{m}^{-1}$ [39]. The essential problem posed by the presence of an electrically conducting liquid is that it provides a parallel path for conduction of an electrical current to that of the wire. If that is significant, one would expect the emf at the wire terminals to depend upon the frequency of measurement [40], even if the magnets are not present. Figure 5 shows the results of measurements of the vibrating-wire cell when it is full of $\left[\mathrm{C}_{2} \mathrm{mim}\right]\left[\mathrm{EtSO}_{4}\right]$ but when the wire is absent. It can be seen that there is indeed a frequency dependence of the modulus of the impedance at low frequencies, but that at the frequencies of interest to measurement (around $1 \mathrm{kHz}$ ) is very weak, and its value is still several orders of magnitude higher than the wire resistance.

In Fig. 6 we provide further evidence because we show the modulus of the impedance of the cell when it contains both the wire and $\left[\mathrm{C}_{2} \mathrm{mim}\right]\left[\mathrm{EtSO}_{4}\right]$ but lacks

Fig. 5 Modulus of impedance of the vibrating-wire cell containing $\left[\mathrm{C}_{2} \mathrm{mim}\right]\left[\mathrm{EtSO}_{4}\right]$, without the wire

Fig. 6 Modulus of impedance of the vibrating-wire cell containing $\left[\mathrm{C}_{2} \mathrm{mim}\right]\left[\mathrm{EtSO}_{4}\right]$, with the wire, but without magnets
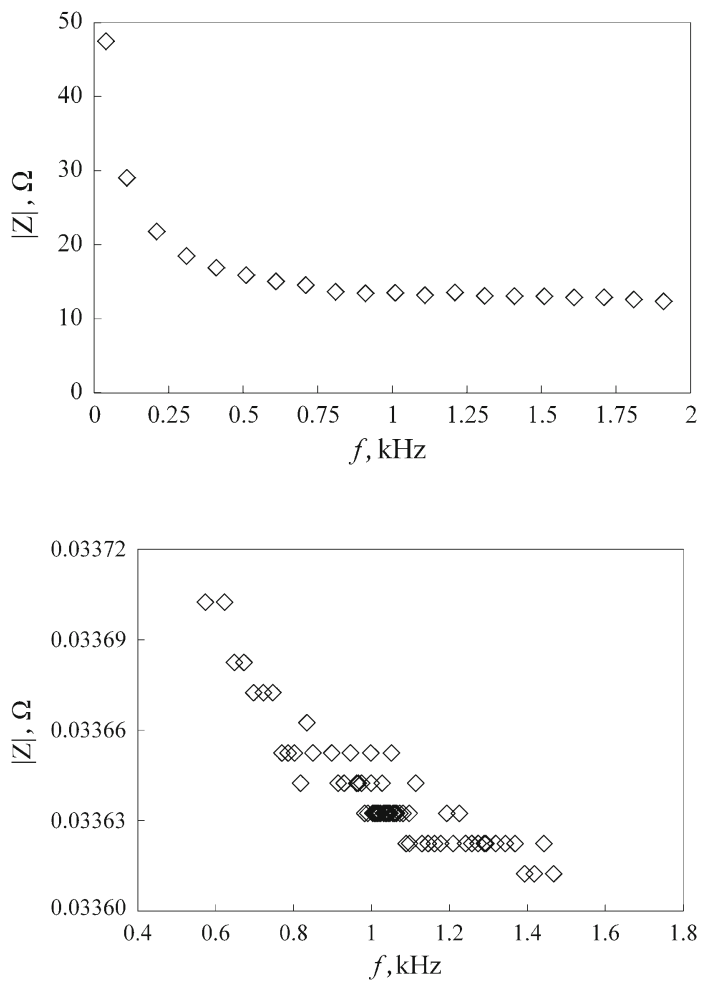
the driving magnets. The impedance variation over the range of frequencies of interest around $1 \mathrm{kHz}$ is only $0.0001 \Omega$, which is entirely negligible for practical purposes. These results illustrate that the instrument can be used for viscosity measurements on this liquid without incurring any significant error because of its electrical conductivity. Evidently this test would need to be repeated for other liquids of higher electrical conductivity before the same statement could be made.

\section{Capillary Viscosity Measurements}

\subsection{Materials}

In the present work three RTILs were used in our viscosity measurements with a suspended level capillary, namely, 1-hexyl-3-methylimidazolium bis[(trifluoromethyl) sulfonyl]imide, $\left[\mathrm{C}_{6} \mathrm{mim}\right]\left[\mathrm{NTf}_{2}\right]$, acquired from IoLiTec (purity higher than $99 \%$ NMR assay, less than $100 \mathrm{mg} \cdot \mathrm{kg}^{-1}$ of halides content); 1-ethyl-3-methylimidazolium ethyl sulfate, $\left[\mathrm{C}_{2} \mathrm{mim}\right]\left[\mathrm{EtSO}_{4}\right]$ (sample $\mathbf{B}$, the same sample from Ref. [22]), obtained from IoLiTec (purity higher than $99 \%$ NMR assay, with less than $100 \mathrm{mg} \cdot \mathrm{kg}^{-1}$ of halides content) and 1-ethyl-3-methylpyridinium ethyl sulfate, $\left[\mathrm{C}_{2} \mathrm{mpy}\right]\left[\mathrm{EtSO}_{4}\right]$, supplied by Solvent Innovation, with a stated minimum purity of $99 \%$. The samples used in this work with the capillary were the same samples used with the vibrating wire in Ref. [22].

Each of the samples was dried under vacuum for about $48 \mathrm{~h}$ at around $323 \mathrm{~K}$, and left under vacuum for several days at room temperature. After drying, the ionic liquids were kept inside a glass vessel, sealed with a PTFE piston valve and a PTFE/rubber septum, under dry nitrogen or helium gas. The experiments and measurements described were also made under a helium or nitrogen atmosphere for the complete set of ionic liquids. The water content of the samples was monitored, before and after the capillary viscosity measurements by Karl-Fisher coulometric titration, using an $831 \mathrm{KF}$ coulometer from Metrohm (Germany).

\subsection{Experimental}

Viscosity capillary measurements were performed using an automatic Schott ViscoSystem ${ }^{\circledR}$ AVS 440 measuring unit fitted with an Ubbelohde viscometer of Type 541 23/IIc from Schott-Geräte, Germany. The Ubbelohde capillary has been calibrated with a standard specimen 100B, from PTB, Germany, as described in Ref. [41]. The capillary was immersed in a silicone oil thermostatic bath (SchottGeräte CT1445). A Thermo NESLAB RTE7 cryostat was used as a cooling source. The temperature of the thermostatic oil was measured, with a $100 \Omega$ platinum resistance thermometer, calibrated by EIA (Portugal) with an overall estimated uncertainty

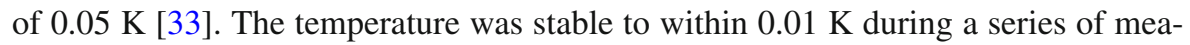
surements. The results of the measurements were accepted when two sets of five measurements were performed, having deviations from the mean smaller than $0.1 \%$. All of the inlets used for air admission to the Ubbelohde capillary were fed with dry 
nitrogen gas. The filling of the Ubbelohde capillary was always made inside a glove box in a dry nitrogen atmosphere.

For the capillary viscosity measurements of a sample of $\left.\left[\mathrm{C}_{2} \mathrm{mpy}_{[}\right] \mathrm{EtSO}_{4}\right]$, the automatic filling controller Schott ViscoSystem ${ }^{\circledR}$ AVS 440, and the oil bath CT1445 with the capillary were inside a glove box in a dry atmosphere of nitrogen. For samples of $\left[\mathrm{C}_{6} \mathrm{mim}\right]\left[\mathrm{NTf}_{2}\right]$ and $\left[\mathrm{C}_{2} \mathrm{mim}\right]\left[\mathrm{EtSO}_{4}\right]$ the automatic filling controller Schott ViscoSystem ${ }^{\circledR}$ AVS 440 was also inside a glove box, in a dry atmosphere of nitrogen. In the latter case, the CT1445 oil bath with the capillary was outside the glove box. However, all the tubes, including the venting and pressure tubes of the capillaries were connected to the filling controller, inside the glove box, by silicone tubes, in order to avoid contact with humid air, during all capillary viscosity measurements. The combined expanded uncertainty, at $95 \%$ confidence level, of the viscosity values obtained using an Ubbelohde capillary is $2 \%$.

\subsection{Surface-Tension Effects on Capillary Viscometry}

Accurate capillary viscometry requires careful attention to the effects caused by interfacial tension on the results, as reported elsewhere by Caetano et al. [26] and mentioned earlier. Our earlier analysis was based on the work of Bauer and Meerlender [25]. According to those studies, the surface-tension effects on the viscosity measurements made with a suspended level Ubbelohde capillary can be evaluated by introducing the correction factor $\chi$ to the Hagen-Poiseuille equation, such that [25]

$$
\nu_{\mathrm{B}, \mathrm{corr}}=K_{0} t\left[1-\chi\left(\frac{\sigma_{0}}{\rho_{0}}-\frac{\sigma_{\mathrm{i}}}{\rho_{\mathrm{i}}}\right)\right]
$$

where $v_{\mathrm{B} \text {, corr }}$ is the corrected kinematic viscosity of the test fluid $i, K_{0}$ is the viscometer constant, and $t$ is the flow time for fluid $i$. In addition, $\sigma$ represents the surface tension of a fluid and $\rho$ is its density. The $\chi$ factor is a constant for a given capillary, and it can be obtained by using two viscosity standards ( 0 and A), according to Ref. [26],

$$
\chi=\frac{1-\left(\frac{v_{\mathrm{A}}}{K_{0} t_{\mathrm{A}}}\right)}{\left(\frac{\sigma_{0}}{\rho_{0}}\right)-\left(\frac{\sigma_{\mathrm{A}}}{\rho_{\mathrm{A}}}\right)}
$$

The subscript (0) refers to the fluid used to calibrate the viscometer and to determine $K_{0}$. The correction shown in Eq. 4 does not include either the kinetic energy correction or the correction owing to the buoyancy effects that are taken into account in the original reference, but were excluded here for simplicity. If the ratio $\sigma / \rho$ of fluid (B) differs substantially from that of the reference fluid used for calibration, the surface-tension correction can be significant [26].

In the present work the viscosities of $\left[\mathrm{C}_{6} \mathrm{mim}\right]\left[\mathrm{NTf}_{2}\right],\left[\mathrm{C}_{2} \mathrm{mim}\right]\left[\mathrm{EtSO}_{4}\right]$, and $\left[\mathrm{C}_{2} \mathrm{mpy}\right]\left[\mathrm{EtSO}_{4}\right]$ were measured with the same Ubbelohde capillary (541 23/IIc) used by Caetano et al. [41]. In that case the value of $\chi$ was determined using two calibrant fluids [26]. For fluid (0) we used PTB, Germany, viscosity reference specimen 


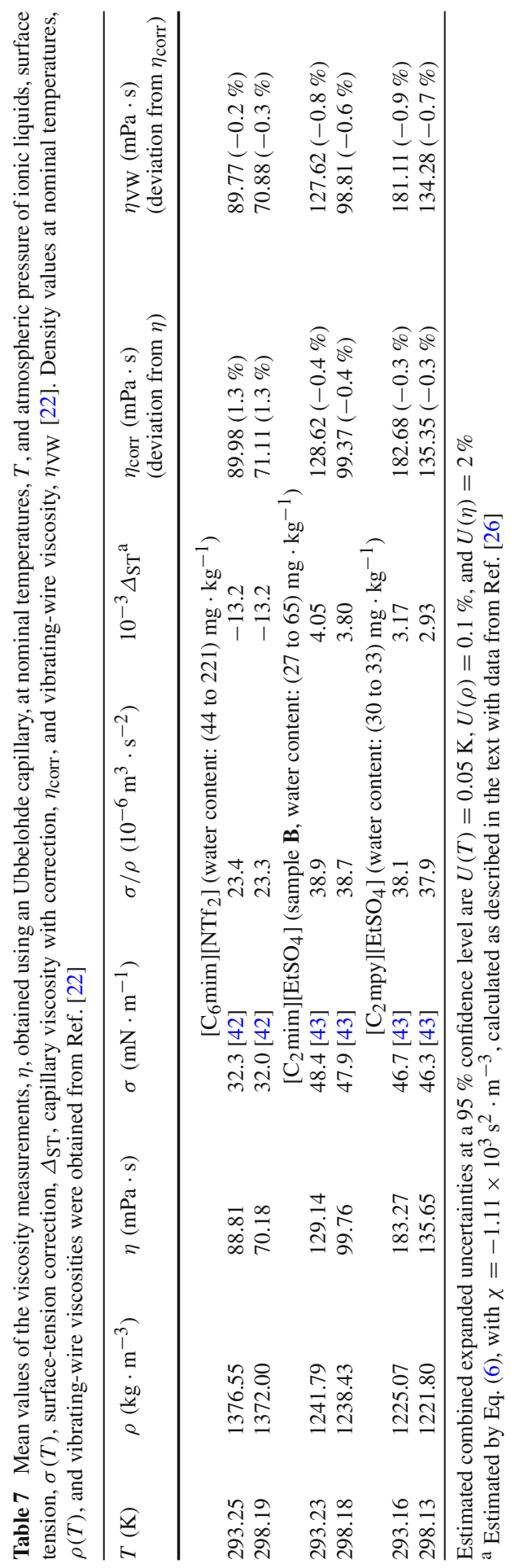


100B where $\sigma / \rho=35.2 \times 10^{-6} \mathrm{~m}^{3} \cdot \mathrm{s}^{-2}$ and for the auxiliary fluid (A), viscosity standard S60 from Paragon, UK, was used, for which $\sigma / \rho=33.3 \times 10^{-6} \mathrm{~m}^{3} \cdot \mathrm{s}^{-2}$ at $298.15 \mathrm{~K}$. The required surface tension of the RTILs was obtained by Carvalho et al. [42] for $\left[\mathrm{C}_{6} \mathrm{mim}\right]\left[\mathrm{NTf}_{2}\right]$ and from Restolho et al. [43] for $\left[\mathrm{C}_{2} \mathrm{mim}\right]\left[\mathrm{EtSO}_{4}\right]$ and $\left[\mathrm{C}_{2} \mathrm{mpy}\right]\left[\mathrm{EtSO}_{4}\right]$.

The data concerning the estimation of the effect of the surface tension on the Ubbelohde capillary measurements are shown in Table 7 for the three samples of ionic liquids studied. These comprise the results of the viscosity measured by the suspended level capillary in the present work, the density and surface tension of the three ionic liquids, with the respective sources, the value of the correction parameter $\chi$ for the capillary used, and the correction due to the surface-tension effect, $\Delta_{\mathrm{ST}}$, which according to Eq. 5, is

$$
\Delta_{\mathrm{ST}}=\left[\chi\left(\frac{\sigma_{\mathrm{i}}}{\rho_{\mathrm{i}}}-\frac{\sigma_{0}}{\rho_{0}}\right)\right]
$$

where subscript $i$ refers to an ionic liquid sample, and subscript (0) refers to the liquid used to calibrate the viscometer.

For comparison, the values obtained for the viscosity of the same samples, obtained by the vibrating-wire technique [22] are also shown in Table 7, for comparison. The density was calculated from data correlations [22], obtained from measurements with a DMA 5000 Anton Paar vibrating U-tube densimeter. The same table then shows the magnitude of the surface-tension correction for each of our three test ionic liquids and illustrates that the correction can be as much as $1.3 \%$ when the $\sigma / \rho$ ratio differs substantially from that of the calibrant fluids. It is noteworthy that the correction is negative for $\left[\mathrm{C}_{6} \mathrm{mim}\right]\left[\mathrm{NTf}_{2}\right]$ and positive for the other RTILs $\left[\mathrm{C}_{2} \mathrm{mim}\right]\left[\mathrm{EtSO}_{4}\right]$ and $\left[\mathrm{C}_{2} \mathrm{mpy}\right]\left[\mathrm{EtSO}_{4}\right]$.

Figures 7,8 , and 9 show the deviations of the viscosity of $\left[\mathrm{C}_{6} \mathrm{mim}\right]\left[\mathrm{NTf}_{2}\right]$, $\left[\mathrm{C}_{2} \mathrm{mim}\right]\left[\mathrm{EtSO}_{4}\right]$, and $\left[\mathrm{C}_{2} \mathrm{mpy}\right]\left[\mathrm{EtSO}_{4}\right]$, with different water contents, measured with
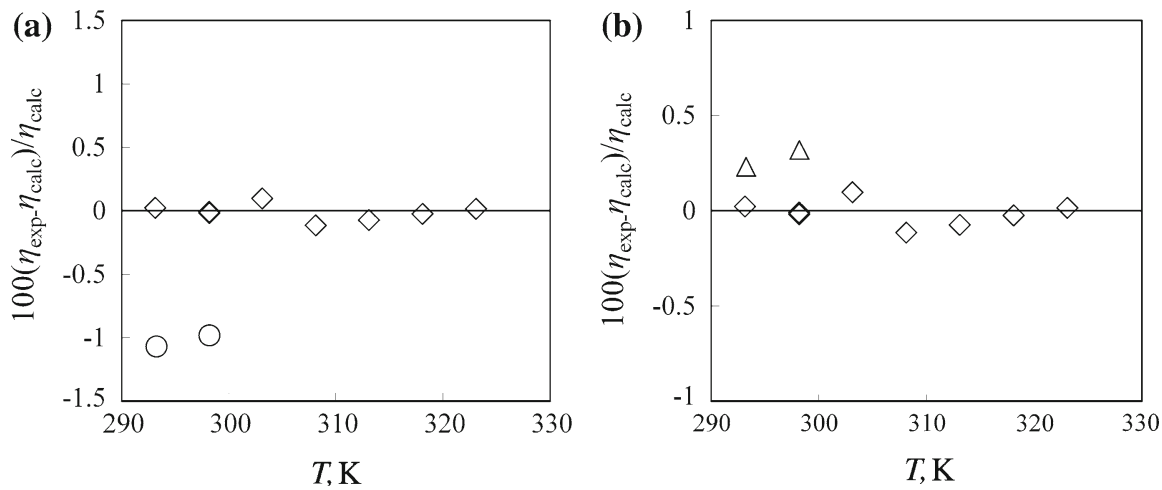

Fig. 7 Deviations of viscosity results for $\left[\mathrm{C}_{6} \mathrm{mim}\right]\left[\mathrm{NTf}_{2}\right]$ obtained in the present work using an Ubbelohde capillary, $w_{\mathrm{H}_{2} \mathrm{O}}$ from (44 to 221$) \mathrm{mg} \cdot \mathrm{kg}^{-1}: \bigcirc$, with no surface-tension correction; $\Delta$, with surface-tension correction; from the correlation obtained with the vibrating-wire (VW) data from Ref. [22]. Also shown are the deviations of the VW data used for the correlation [22]: $\diamond, w_{\mathrm{H}_{2} \mathrm{O}}$ from (25 to 89) $\mathrm{mg} \cdot \mathrm{kg}^{-1}$ 

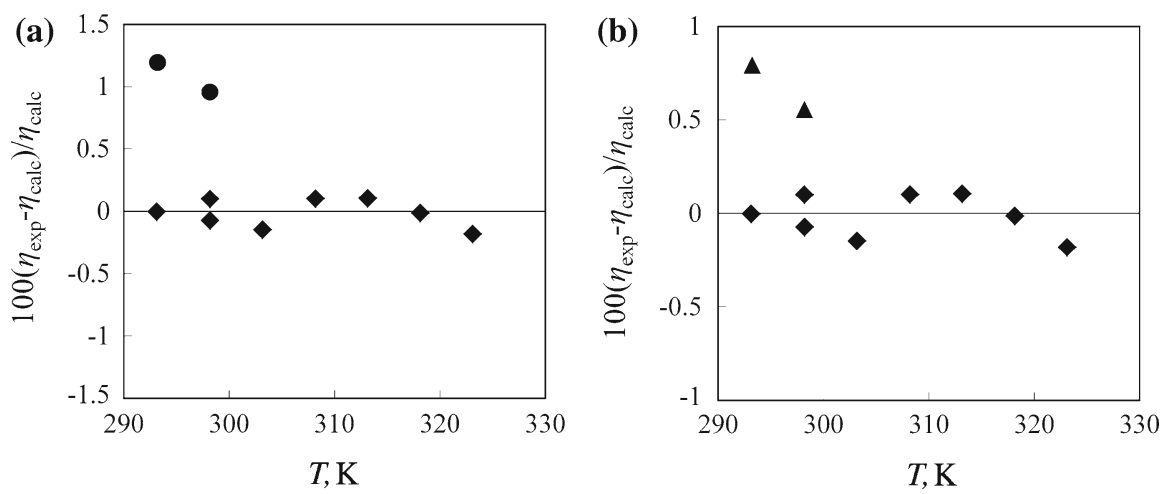

Fig. 8 Deviations of viscosity results for $\left[\mathrm{C}_{2} \mathrm{mim}\right]\left[\mathrm{EtSO}_{4}\right]$ obtained in the present work using an Ubbelohde capillary, $w_{\mathrm{H}_{2} \mathrm{O}}$ from $(27$ to 65$) \mathrm{mg} \cdot \mathrm{kg}^{-1}:$ with no surface-tension correction; $\boldsymbol{\Delta}$, with surface-tension correction; from the correlation obtained with the vibrating-wire (VW) data of $\left[\mathrm{C}_{2} \mathrm{mim}\right]\left[\mathrm{EtSO}_{4}\right]$ sample $\mathbf{B}$, from Ref. [22]. Also shown are the deviations of the VW data used for the correlation [22]: $\downarrow, w_{\mathrm{H}_{2} \mathrm{O}}$ from (6 to 7$) \mathrm{mg} \cdot \mathrm{kg}^{-1}$
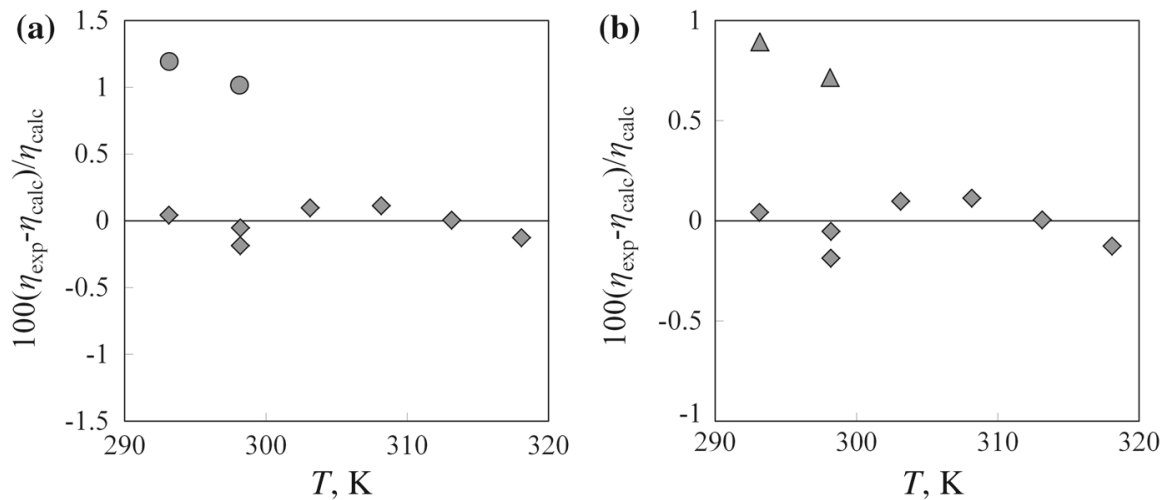

Fig. 9 Deviations of viscosity results for $\left.\left[\mathrm{C}_{2} \mathrm{mpy}_{[}\right] \mathrm{EtSO}_{4}\right]$ obtained in the present work using an Ubbelohde capillary, $w_{\mathrm{H}_{2} \mathrm{O}}$ from (30 to 33 ) $\mathrm{mg} \cdot \mathrm{kg}^{-1}: \mathrm{O}$, with no surface-tension correction; $\triangle$, with surface-tension correction; from the correlation obtained with the vibrating-wire (VW) data from [22]. Also shown are the deviations of the VW data used for the correlation [22]: $\diamond, w_{\mathrm{H}_{2} \mathrm{O}}$ from (22 to 74) $\mathrm{mg} \cdot \mathrm{kg}^{-1}$

our vibrating-wire viscometer [22] and with the Ubbelohde capillary viscometer in the present work, from the correlation of the vibrating-wire results [22]. In Figs. 7a, $8 \mathrm{a}$, and $9 \mathrm{a}$ the capillary results are not corrected for the surface-tension effect. The deviations do not exceed $2 \%$ but are evidently systematic. This deviation is within the estimated expanded uncertainty, $U(\eta)$, at a $95 \%$ confidence level, of the vibrating-wire results [22]. In Figs. 7b, 8b, and 9b the capillary results are shown after application of the surface-tension correction. It is noteworthy that the corrections have decreased the deviations from the vibrating-wire data that are themselves intrinsically free of surface-tension effects. The deviations do not exceed $1 \%$ for all measured RTILs. The deviations are negative for $\left[\mathrm{C}_{6} \mathrm{mim}\right]\left[\mathrm{NTf}_{2}\right]$ and positive for $\left[\mathrm{C}_{2} \mathrm{mim}\right]\left[\mathrm{EtSO}_{4}\right]$ and $\left[\mathrm{C}_{2} \mathrm{mpy}\right]\left[\mathrm{EtSO}_{4}\right]$. These results indicate that with appropriate care it is possible 
to secure agreement between measurements of the viscosity of RTILs with different primary viscometers that lie within the mutual uncertainty of the experiments.

\section{Conclusions}

The paper has set out some of the evidence that supports concerns that the application of standard methods for measuring the viscosity of liquids to RTILs needs to be carefully analyzed. Several causes of these discrepancies have been identified that involve the purity and handling of samples and the development and use of full working equations for viscometers. It has been shown how proper precautions and methodology can reduce the discrepancies.

It is to be hoped that authors, referees, and editors will keep these observations in mind when considering publication of viscometric data for these and other fluids to preserve the integrity of the science of viscometry.

Acknowledgments This work was developed under Projects PTDC/QUI/66826/2006 and PTDC/EQUEPR/103505/2008 and was also partially supported by the Multiannual Funding to Centro de Química Estrutural and by the Strategic Project PEst-OE/QUI/UI0100/2011, all funded by Fundação para a Ciência e a Tecnologia (FCT, Portugal). The authors acknowledge the permission of Elsevier B.V. to reproduce in this article (see Tables 1,2) Tables 6a and 6b of the paper "Viscosity Measurements of Three Ionic Liquids Using the Vibrating Wire Technique", taken from Ref. [22]. The authors also acknowledge the grant attributed to J.C.F.D. under the above mentioned project PTDC/66826/2006. Furthermore, J.C.F.D. thanks FCT, Portugal, for his PhD grant (SFRH / BD / 66736 / 2009).

\section{References}

1. G. Maitland, M. Rigby, E.B. Smith, W.A. Wakeham, Intermolecular Forces: Their Origin and Determination (Clarendon Press, Oxford, 1987)

2. W.A. Wakeham, A. Nagashima, J.V. Sengers (eds.), Experimental Thermodynamics, Measurement of the Transport Properties of Fluids, vol. III (Blackwell Scientific for International Union of Pure and Applied Chemistry, Oxford, 1991)

3. Achievements in Stratospheric Ozone Protection: Progress Report (U.S. Environmental Protection Agency, Office of Air and Radiation, April 2007)

4. Ozone Secretariat, The Montreal Protocol on Substances that Deplete the Ozone Layer, as either adjusted and/or amended in London 1990; Copenhagen 1992; Vienna 1995; Montreal 1997; Beijing 1999, United Nations Environment Program, March 2000

5. Office for Official Publications of the European Communities, Montreal Protocol: Air Environment (European Commission, 2007)

6. M.J. Assael, W.A. Wakeham, Int. J. Refrig. 18, 335 (1995)

7. C.A. Nieto de Castro, J. Mol. Liq. 156, 10 (2010)

8. K. Marsh, J.F. Brennecke, R.D. Chirico, M. Frenkel, A. Heintz, J.W. Magee, C.J. Peters, L.P.N. Rebelo, K.R. Seddon, Pure Appl. Chem. 81, 781 (2009)

9. R.D. Chirico, V. Diky, J.W. Magee, M. Frenkel, K. Marsh, Pure Appl. Chem. 81, 791 (2009)

10. C.A. Nieto de Castro, F.J.V. Santos, J.M.N.A. Fareleira, W.A. Wakeham, J. Chem. Eng. Data 54, 171 (2009)

11. W.A. Wakeham, M.A. Assael, J.K. Atkinson, J. Bilek, J.M.N.A. Fareleira, A.D. Fitt, A.R.H. Goodwin, C.M.B.P. Oliveira, Int. J. Thermophys. 28, 372 (2007)

12. J.L. Copeland, Transport Properties of Ionic Liquids (Gordon and Breach, New York, 1974)

13. B.D. Fitchett, T.N. Knepp, J.C. Conboy, J. Electrochem. Soc. 151, E219 (2004)

14. J.M. Crosthwaite, M.J. Muldoon, J.K. Dixon, J.L. Anderson, J.F. Brennecke, J. Chem. Thermodyn. 37, 559 (2005)

15. H. Tokuda, K. Hayamizu, K. Ishii, M.A.B.H. Susan, M. Watanabe, J. Phys. Chem. B 109, 6103 (2005) 
16. H. Tokuda, S. Tsuzuki, M. Susan, K. Hayamizu, M. Watanabe, J. Phys. Chem. B 110, 19593 (2006)

17. A. Muhammad, M.I.A. Mutalib, C.D. Wilfred, T. Murugesan, A. Shafeeq, J. Chem. Thermodyn. 40, 1433 (2008)

18. A. Ahosseini, A.M. Scurto, Int. J. Thermophys. 29, 1222 (2008)

19. J.A. Widegren, J.W. Magee, J. Chem. Eng. Data 52, 2331 (2007)

20. F.J.V. Santos, C.A. Nieto de Castro, P.J.F. Mota, A.P.C. Ribeiro, Int. J. Thermophys. 31, 1869 (2010)

21. M.E. Kandil, K.N. Marsh, A.R.H. Goodwin, J. Chem. Eng. Data 52, 2382 (2007)

22. J.C.F. Diogo, F.J.P. Caetano, J.M.N.A. Fareleira, W.A. Wakeham, Fluid Phase Equilib. 353, 76 (2013). doi:10.1016/j.fluid.2013.05.012

23. K.N. Marsh, Pure Appl. Chem. 72, 1809 (2000)

24. M. Kwata, K. Kurase, A. Nagashima, K. Yoshida, in Measurement of the Transport Properties of Fluids, vol. III, ed. by W.A. Wakeham, A. Nagashima, J.V. Sengers (Blackwell Scientific Publications, Oxford, 1991) pp. 7-48

25. H. Bauer, G. Meerlender, Rheol. Acta 23, 514 (1984)

26. F.J.P. Caetano, J.M.N.A. Fareleira, A.C. Fernandes, C.M.B.P. Oliveira, A.P. Serro, I.M. Simões de Almeida, W.A. Wakeham, Fluid Phase Equilib. 245, 1 (2006)

27. Anton Paar, GmbH; Stabinger Viscometer: Pressen Product. http://www.anton-paar.com/001/en/Web/ Document/download/1603?clng=en. Accessed 8 Sept 2012

28. Anton Paar, GmbH; Stabinger Viscometer. http://www.anton-paar.com/001/en/Web/Document/ download/1605?clng=en. Accessed 8 Sept 2012

29. Anton Paar, GmbH; SVM 3000 Stabinger Viscometer. http://www.anton-paar.com/001/en/Web/ Document/download/1039?clng=en. Accessed 8 Sept 2012

30. K.R. Seddon, A. Stark, M.J. Torres, Pure Appl. Chem. 72, 2275 (2000)

31. C.A. Nieto de Castro, E. Langa, A.L. Morais, M.L.M. Lopes, M.J.V. Lourenco, F.J.V. Santos, M. Santos, J.N.C. Lopes, H.I.M. Veiga, M. Macatrao, J. Esperanca, C.S. Marques, L.P.N. Rebelo, C.A.M. Afonso, Fluid Phase Equilib. 294, 157 (2010)

32. F.J.P. Caetano, J.M.N.A. Fareleira, C.M.B.P. Oliveira, W.A. Wakeham, J. Chem. Eng. Data 50, 201 (2005)

33. J.C.F. Diogo, F.J.P. Caetano, J.M.N.A. Fareleira, W.A. Wakeham, C.A.M. Afonso, C.S. Marques, J. Chem. Eng. Data 57, 1015 (2012)

34. T. Retsina, S.M. Richardson, W.A. Wakeham, Appl. Sci. Res. 43, 325 (1987)

35. A.A.H. Pádua, J.M.N.A. Fareleira, J.C.G. Calado, W.A. Wakeham, Int. J. Thermophys. 17, 781 (1996)

36. J. Vaughan, J. Haggins, D. Dreisinger, ECS Trans. 2, 381 (2006)

37. J. Vila, P. Gines, J.M. Pico, C. Franjo, E. Jimenez, Fluid Phase Equilib. 242, 141 (2006)

38. Conductivity Standard $0.01 \mathrm{D}, 1408 \mu \mathrm{S} / \mathrm{cm} \pm 0.5 \%$ @ $25^{\circ} \mathrm{C}$, manufactured by HACH LANGE GmbH for Radiometer Analytical SAS, Serial Number C01622, Calibration Mark 000335/DKD-K-47901/1003 (Villeurbanne Cedex, France, 2010)

39. Conductivity Standard $0.1 \mathrm{D}, 12.85 \mathrm{mS} / \mathrm{cm} \pm 0.35 \%$ @ $25^{\circ} \mathrm{C}$, manufactured by HACH LANGE GmbH for Radiometer Analytical SAS, Serial Number C01600, Calibration Mark 000313/DKD-K-47901/1003 (Villeurbanne Cedex, France, 2010)

40. R.A. Robinson, R.H. Stokes, Electrolyte Solutions, 2nd edn. (Butterworths, London, 1959)

41. F.J.P. Caetano, J.M.N.A. Fareleira, A.P. Fröba, K.R. Harris, A. Leipertz, C.M.B.P. Oliveira, J.P. Martin Trusler, W.A. Wakeham, J. Chem. Eng. Data 53, 2003 (2008)

42. P.J. Carvalho, M.G. Freire, I.M. Marrucho, A.J. Queimada, J.A.P. Coutinho, J. Chem. Eng. Data 53, 1346 (2008)

43. J. Restolho, J.L. Mata, B. Saramago, J. Colloid Interface Sci. 340, 82 (2009) 